\title{
STUDIES ON PREPARATION OF JAGGERY GRANULES WITH NUCLEATION TECHNIQUE
}

\author{
DILIP PAWAR ${ }^{1}$, PRAKASH UNDE ${ }^{2} \&$ VIVEK KANAWADE ${ }^{3}$ \\ ${ }^{1}$ Scientist, Agro-Produce Processing Division, ICAR-CIAE, Bhopal, Mathya Pradhesh, India \\ ${ }^{2}$ Ex Professor and Head, Department of APE, MPKV, Rahuri, Maharashtra, India \\ ${ }^{3}$ Deputy Director of Research, MPKV, Rahuri, Maharashtra, India
}

\begin{abstract}
Experiments were carried out for the preparation of jaggery granules with the technique of nucleation. The

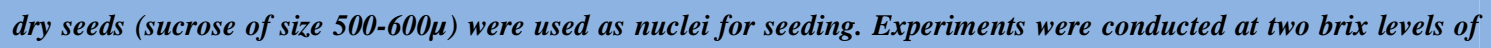
jaggery syrup with three seeding levels of dry seeds as 50, 100 and $150 \mathrm{~g} / \mathrm{L}$ to study the effect of seeding on percentage recovery of jaggery granules of different size. The results revealed that the per cent recovery of fine granules $(<1000 \mu)$ was significantly decreased with increase in seeding level. The recovery of medium (1000-2000 $\mu$ ) and coarse (2000$3000 \mu$ ) size granules was increased with increase in seeding levels indicating the effect of nucleation. At $95^{\circ} \mathrm{B}$ the recovery of fine, medium and coarse size granules was found to be 44.50, 25.92 and 29.58 per cent, respectively under control, whereas at maximum seeding level of $150 \mathrm{~g} / \mathrm{L}$, it was $25.64,35.99$ and 40.29 per cent, respectively for fine, medium and coarse granules. Similar effect was attributed at $85^{\circ} \mathrm{B}$. Moreover, the color of jaggery granules prepared at $85^{\circ} \mathrm{B}$ was yellowish compared to $95^{\circ} \mathrm{B}$. The nucleation in jaggery syrup during cooling stage enhances the process of granulation. All size granules (fine, medium and coarse) were seen attractive in terms of colour, appearance and texture.

KEYWORDS: Jaggery, Size, Clarification, Storage, Packaging \& Value Addition
\end{abstract}

Received: Jul 10, 2017; Accepted: Jul 25, 2017; Published: Aug 01, 2017; Paper Id.: IJASRAUG201779

\section{INTRODUCTION}

Jaggery (also called as Gur in India, Desi in Pakistan, Panela in Mexico and South America, Jaggery in Burma and African countries, Hakuru in Sri Lanka and Naam Taanoi in Thailand) and Khandsari are traditional sweeteners which are produced in addition to sugar from sugarcane (Thakur, 1999). These traditional sweeteners are the natural mixture of sugar and molasses. If pure clarified sugar juice is boiled, what is left (usually possessing sucrose (65-85 per cent) as solid jaggery? Khandsari sugar is a finely granulated, crystallized sugar that contains 94-98 per cent sucrose (Mungare et al, 1999). With better standard of living and higher per capita income, the sweetener demand has shifted to white sugar containing purely sucrose (99.70 per cent). Therefore jaggery sector has got a setback to some extent. The percent utilization of sugarcane for production of jaggery and khandsari was 37.40 in the year 1990-91 and it has declined to 16.90 in the year 2011-12 (Co-operative sugar, 2013).

Predominantly, the Indian population is rural, as above 65 per cent people lives in rural villages. The majority of the population suffers due to under nutrition and malnutrition, as the common Indian diet is deficient in nutrition. The health food is considered to be the food which is beneficial to health, beyond a normal healthy diet required for human nutrition. It is also referred to as functional food, i.e. food for which a specific claim of 
health benefits is made, such as that consumption of the food may prevent diseases. The magnesium strengthens the nervous system, helps to relax our muscles, gives relief from fatigue and takes care of our blood vessels. It also, along with selenium, acts as an antioxidant and has property to scavenge free radicals from our body. The potassium and low amount of sodium present in jaggery maintain the acid balance in the body cells and also combat acids and acetone, and control our blood pressure. Iron helps to prevent anemia. It also helps to relieve tension and takes care of asthma, as it has anti-allergic properties. Ayurveda also prescribes jaggery for migraine and at the time of post pregnancy for removing all clotted blood from the body, within 40 days after the birth of a baby. The preventive ability of jaggery on smoker's smoke-induced lung lesions suggest the potential of jaggery as a protective food for workers in dusty and smoky atmosphere even for those who are engaged in woolen industries, the wool dust clogged in the food pipe could be cleared with jaggery. Thus, jaggery helps to breathe easier and counters the pollution problems naturally. The moderate amount of calcium, phosphorous and zinc helps to maintain optimum health. It also purifies the blood, prevents rheumatic afflictions and bile disorders and thus helps to cure jaundice.

There are mainly three forms of jaggery viz, solid jaggery, liquid jaggery and granular jaggery. In India about 80 per cent jaggery prepared is in solid form and remaining 20 per cent includes liquid and granular jaggery. While concentrating, when the liquid content reaches to $60-70^{\circ} \mathrm{B}$ with a corresponding temperature of $105-108^{\circ} \mathrm{C}(\mathrm{depending}$ on the cane varieties and agro-climatic zones), the intermediate product collected is popularly known as liquid jaggery (Rao, et al, 2007 and Nevkar, 2011). The granular jaggery is also popular particularly among rural regions. The quality crystalline granular jaggery is prepared by adjusting juice $\mathrm{pH}$ to 6.0-6.2 by adding lime solution followed by juice boiling and clarification simultaneously using deola (H. ficulneus) mucilage as a clarificant (Rao, et al, 2007; Shridevi, 2008 and Shigh, et al, 2011). A quality jaggery is golden yellow in colour, hard in texture, crystalline in structure, sweet in taste, less in impurities and low in moisture. The quality of jaggery is influenced by the variety of cane, quantity and quality of fertilizers applied, quality of irrigation water and the method of processing adopted.

The changing taste and preferences for food and food products and increasing awareness for natural products in the global markets has created new avenues for export of natural products. The liberalization of Indian economy has provided new opportunities to take the advantage of rising demand in the world markets for various natural products like jaggery. India has enough potential for production and export of jaggery, which can be promoted by adopting efficient technology for producing standard quality jaggery demanded in the international markets. This indigenous product may be translated into branded one and should be bargained in the world market on the ground of its nutrient value, purity and being natural.

Though the industry is at cottage level, considerable research has reported by some authors. Rao et al, (2007) reported that granular form of jaggery with its low moisture content (1-2 per cent d. b.) offers the advantages like long shelf life up to two years, easy handling, formulation of the product free from hazardous chemicals like hydros, super phosphate, phosphoric acid etc. The same author (2008) prepared jaggery granules and studied it's the physical and thermal properties. The coarse jaggery powder having particle size in the range $0.500-0.780 \mathrm{~mm}$ was found more acceptable among other sizes of powder after six months of storage in terms of chemical and organoleptic characters, Unde et al. (2011). Nevkar et al. (2011), conducted studies on standardization of jaggery powder production process and stated that for good friable crystalline powder, striking point temperature of jaggery should be increased by $2^{\circ} \mathrm{C}$ i.e. from 118 to $120^{\circ} \mathrm{C}$. Tray dried jaggery was collected for crushing in hammer mill with 16 number of beaters. The 5 mm concave size recorded 
highest powder making capacity $(69.80 \mathrm{~kg} / \mathrm{h})$ and significant highest efficiency (64.84\%). Said and Pradhan (2013) reviewed that the granular jaggery is also popular particular among the rural areas. The quality crystalline granular jaggery is prepared by adjusting juice $\mathrm{pH}$ to $6.0-6.2$ by adding lime solution followed by juice boiling and clarified simultaneously using deola (H. ficulneus) mucilage as a clarificant. The striking point temperature for powdery jaggery ranges between $120^{\circ} \mathrm{C}$ and $122^{\circ} \mathrm{C}$ (Rao et al, 2007; Sridevi, 2008 and Singh et al, 2011).

The demand for jaggery granules and small cubes, as a sweetener is increasing now a days in domestic as well international market. Granular and cubic shape jaggery with its low moisture content offers numerous advantages like extended storage life, easy handling, handy packaging and distribution. However, the traditional large sized lumps of the jaggery pose problems in moulding, packaging, handling and storage. Keeping these points in view, research work was carried to prepare jaggery granules with the application of nucleation technique using dry seeds.

\section{MATERIALS AND METHODS}

\section{Sugarcane}

Sugarcanes (Co 92005) with the harvesting period of 12-14 months, which are considered good for jaggery making, were procured from research farm, RSJRS Kolhapur as and when required. The selected sugarcanes were harvested close to the ground level; green tops and leaves were removed and immediately taken for extraction of juice.

\section{Chemicals}

The chemicals such as lime (calcium hydroxide), bhendi mucilage, dry seeds, mineral oil and distilled water were used for the experimental work.

\section{Experimental Methods}

The experiments were carried out with laboratory scale experimental setup at RSJRS, Kolhapur.

\section{Extraction of Juice}

Juice was extracted by passing the canes through the electrically operated horizontal roller crusher having three stainless steel corrugated rollers. The bagasse obtained from the first pass was passed again through the crusher to extract more juice with greater purity. Juice was immediately taken for the further processing.

\section{Pre-Processing of Juice}

\section{Filtration}

The extracted juice was filtered through a muslin cloth $(100 \mu)$ to remove insoluble impurities. The method was suggested in the CFTRI report to APMC, Chamaraja nagar on 'Manufacture of Quality Jaggery'. The semi clear juice was immediately taken for boiling in boiling pan. Figure 1 shows process flow chart for preparation of clarified juice. 


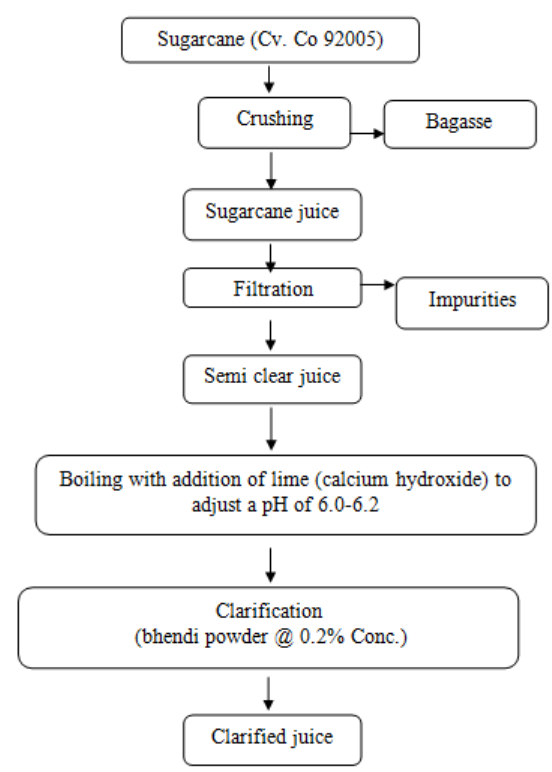

Figure 1: Preparation of Clarified Sugarcane Juice

\section{Boiling and Clarification}

The filtered juice was boiled in open pan (made of SS 304, 30 lit. juice capacity). The heat of boiling was supplied with electrically operated gas fired furnace. The boiling temperature was measured with electronic thermometer. The scum collected at the top was removed with a wooden ladle. Herbal clarificant i.e. bhendi mucilage was added during boiling for removing soluble impurities. The lime was added in the juice to adjust the $\mathrm{pH}$ of 6.2-6.4 for the preparation of quality jaggery.

\section{Nucleation}

The technique of nucleation was used for the preparation of jaggery granules. The technique involves addition of artificial nucleolus during the process of crystallization. The externally added nuclei develop with coating of saccharide on it. The dry seeds (sucrose 500-600 $\mu$ ) were used as nuclei for production of jaggery granules. The seeds were added at two different brix levels as $92^{\circ}$ brix and $85^{\circ}$ brix and 50,100 and $150 \mathrm{~g} / \mathrm{L}$ as three different quantities of dry seeds.

\section{Stirring, Scraping and Rubbing}

The stirring, scraping and rubbing are the three principle actions required to form jaggery granules. A hand scraper made of steel was used for the purpose. The dry seeds were added in a given proportion and were stirred initially to distribute the nucleus uniformly. The material got solidifies because of cooling cum crystallization. Then simultaneous actions of scraping and crushing were used to convert material into granules.

\section{Granule Processing}

The process flow chart for preparation of jaggery granules is given in Figure 2 with some processing operations after production of granules. 


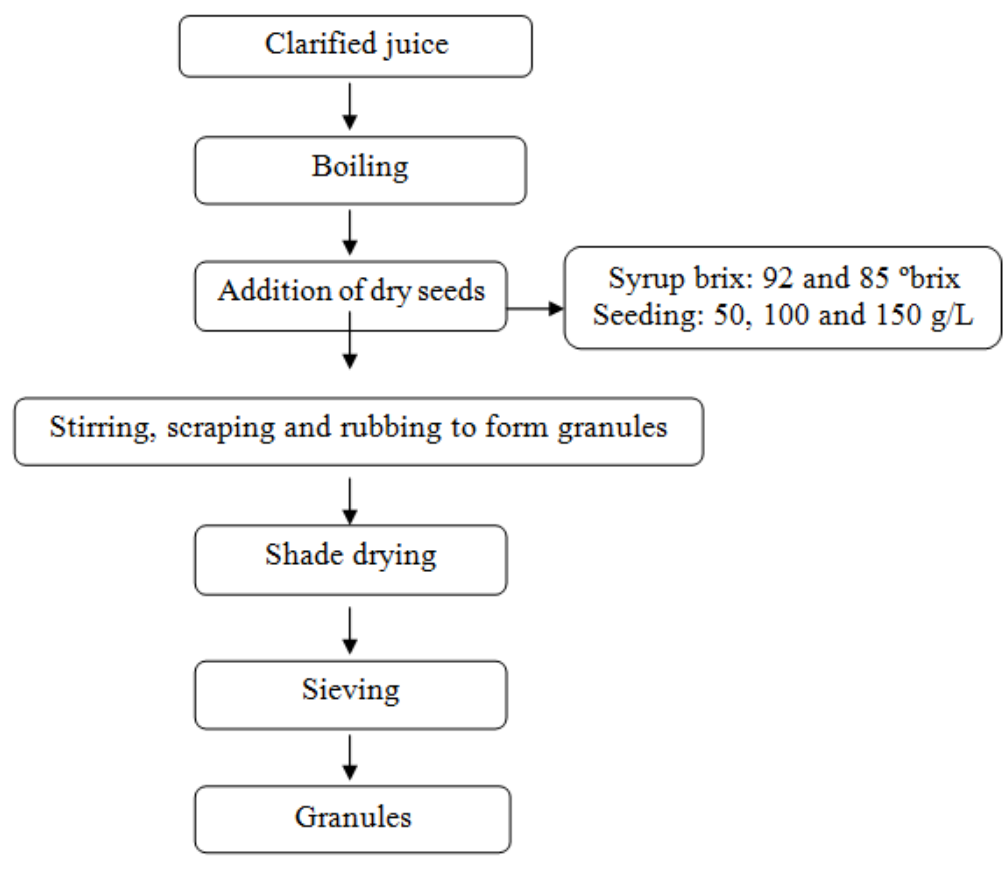

Figure 2: Preparation of Jaggery Granule

\section{Shade Drying}

The granules formed were dried in shade for a period of 2-3 hours to reduce its moisture content to 3-5 per cent (d.b.). The samples were spread uniformly in a tray, covered with a fine mesh cloth and kept in shade for drying. The prepared samples were uniformly spread on a tray and covered with a fine mesh cloth and kept in shade for a period of 2-3 $\mathrm{h}$ to reduce its moisture content up to 3-5 per cent (d.b).

\section{Sieving}

The dried granules were fractionated graded into three fractions $v i z$, less than $1000 \mu$, in between $1000-2000 \mu$ and greater than $2000 \mu$. The standard test sieves were used for this purpose.

\section{RESULTS AND DISCUSSIONS}

\section{Effect of Seeding Level on Recovery of Different Size Granules at $95^{\circ} \mathrm{B}$}

Effect of three seeding levels viz, 50, 100 and $150 \mathrm{~g} / \mathrm{L}$ along with control (without seeding) on recovery of different size granules prepared at two brix levels $\left(95\right.$ and $\left.85^{\circ} \mathrm{B}\right)$ are presented in Figure 3 and 4 . It was observed from Figure 1 that the percent recovery of fine granules seems to decrease with increase in seeding levels. The results showed the statistically significant effect $(\mathrm{p}>0.001)$ at 1 per cent level of significance. At control condition (without seeding), the recovery was found to be 44.50 per cent and it was decreased to 25.64 per cent at a seeding level of $150 \mathrm{~g} / \mathrm{L}$. Among the different models, the polynomial models $\left(\mathrm{R}^{2}=0.98\right)$ was seems to be best fitted compared to all other models having maximum $\mathrm{R}^{2}$ value power model $\left(\mathrm{R}^{2}=0.93\right)$.

The recovery of medium and coarse size granules was reported to be increased with increase in seeding levels. The percent recovery of both size of granules i.e. medium $(p=0.005)$ as well as coarse $(p=0.014)$ was found to be statistically significant with at 1 per cent level of significance. The analysis showed that the polynomial model fits better 
for the simulation of effect of seeding levels on recovery of medium as well as coarse size jaggery granules. The values of per cent recovery at control were seen as 25.92 per cent for medium and 29.58 per cent for coarse size granules. At maximum seeding level of $150 \mathrm{~g} / \mathrm{L}$, it was increased to 35.99 per cent and 40.29 per cent for medium and coarse size granules, respectively.

The findings of decreased in percentage of fine granules and increased in percentage of medium and coarse size granules was might be due to nucleation. During nucleation, the saccharose of jaggery syrup gets accumulated on the added particles of dry seeds and helps to increase its crystal size (Madaria and Rao, 2012 and Aider et $a l$, 2007). Suwansri et al. (2007) concluded that addition of external nuclei such as brown sugar enhances the phenomena of crystallization leads to increase in uniform crystal growth. Thus, it could be confirmed that addition of dry seeds during cooling cum crystallization period of jaggery leads to increase in size of crystals and uniform stirring and scraping action attributed to the process of granulation. Moreover, in the present study the stirring and scraping action was achieved by manuals means using hand scraper made of stainless steel.

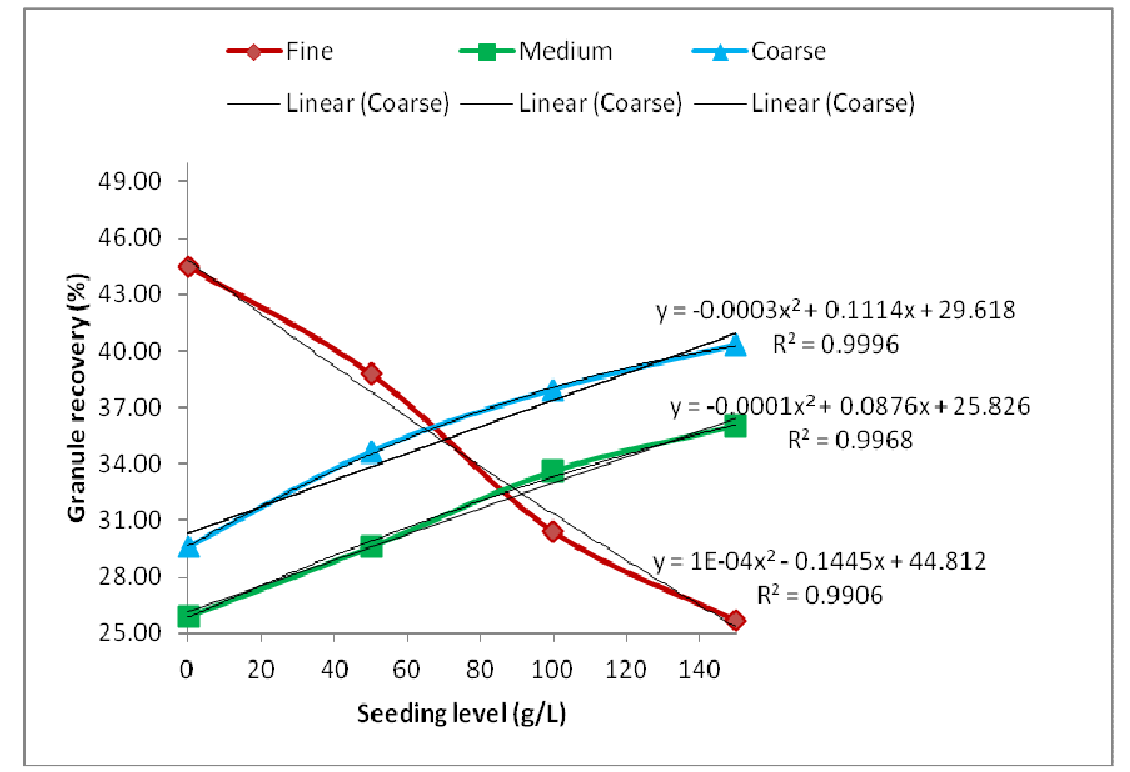

Figure 3: Effect of Seeding Level on Recovery of Different Size Granules at $95^{\circ} \mathrm{B}$

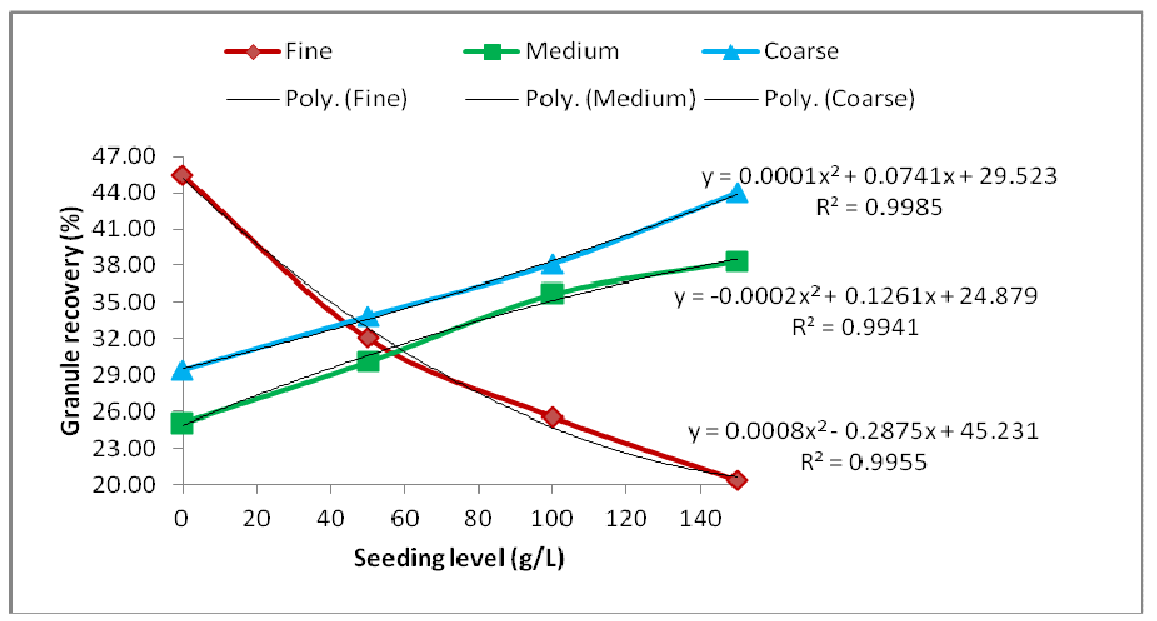

Figure 4: Effect of Seeding Level on Recovery of Different Size Granules at $85^{\circ}$ B 
In case of control sample, since the external nuclei were not available, the granule growth was not uniform and the stirring and scraping actions produced more percentage of fine granules compared to medium and coarse size granules. Earlier studies revealed that jaggery granules of larger sizes were better for its storage (Kudtarkar et al. 2014). Therefore, the nucleation technique used in present study could be feasible to produce quality jaggery granules with better storability. However, the appearance and texture of fine granules was attractive (Figure 4.1 and 4.2) and it was found acceptable.

\section{Effect of Seeding Level on Recovery of Different Size Granules at $85^{\circ} \mathrm{B}$}

There was non-significant effect on the recovery of the different granules size when prepared at $85^{\circ} \mathrm{B}$ level. It was observed that the percentage of fine granules decreased whereas for medium and coarse granules it was increased (Figure 4). The different models viz, linear and non-linear (polynomial, logarithmic and power law) was used to compare the best model to observe the goodness of fit to the data. Among the different models used, the polynomial model was found to be best fitted to for seeding levels and granule recovery. The best regression model which showed relationship between seeding levels and granule recovery in the form of polynomial equation with the higher value of coefficient of determination (R2) as $0.995,0.994$ and 0.996 for fine, medium and course, respectively.

The effect of brix's levels on the quality (colour) of the jaggery granules could be observed visually as shown in Figure 5. It was observed seen that the colour of granules obtained at $85^{\circ} \mathrm{B}$ was less brown in comparison of $95^{\circ} \mathrm{B}$. The darker colour of granules prepared at $95^{\circ} \mathrm{B}$ was might be due to caramelization of sucrose at higher temperature.

\section{CONCLUSIONS}

The technique of nucleation was found to be suitable for the preparation of jaggery granules. Increasing seeding levels increased the recovery of medium and coarse size granules and conversely decreased the fine granule recovery. All size granules (fine, medium and coarse) were visually more acceptable in terms of colour, appearance and texture. The brix levels did not affect granule recovery however; the granules obtained at $85^{\circ} \mathrm{B}$ were yellowish in colour compared to $95^{\circ} \mathrm{B}$.

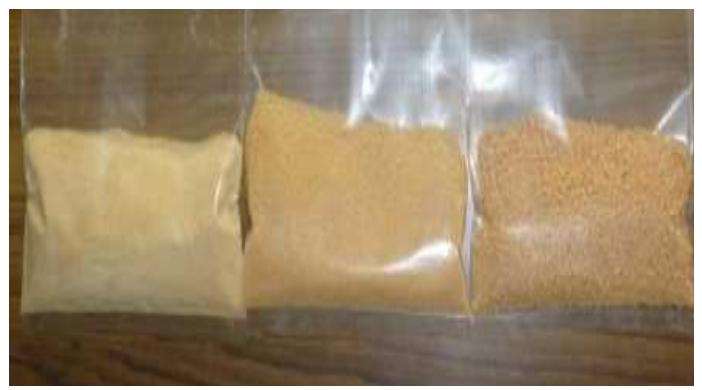

$95^{\circ} \mathrm{B}$

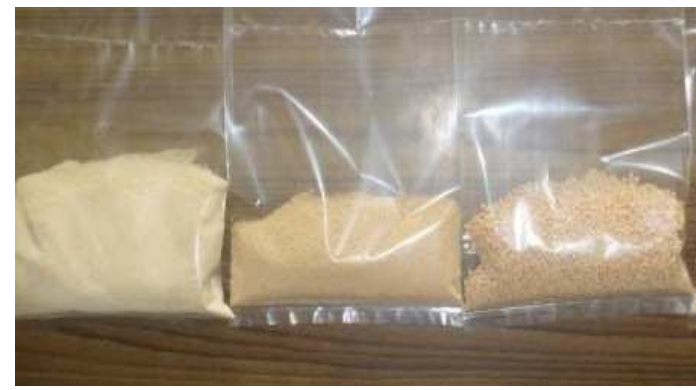

$85^{\circ} \mathbf{B}$

Figure 5: Jaggery Granules of Different Size

\section{REFERENCES}

1. Madariya, P. B. and Rao, K.J. (2012). A study on utilization of whey in jaggery production. Sugar Tech, 14(3), 295-303.

2. Aider, M, Halleux, D.D. and Belkacemi, K. (2007). Production of granulated sugar from maple syrup with high content of inverted sugar. Journal of Food Engineering, 80, 791-797.

3. Co-operative sugar, 2013. 45(1).

4. Kudtarkar, U.S, Nevkar, G.S. and Gaikwad, B.G. (2014). Effect of size and packaging on storability of jaggery powder. Proceedings of National meet on modernization of jaggery industry in India, ICAR-Indian Institute of Sugarcane Research, 
Lucknow.

5. Mungare, T.S, Jadhav, H.D, Shinde, U.S, Jadhav, B.S. and Singh, J. (1999). Status of khandsari industry in Maharashtra, Proc Ntl Seminar on Status, problems and prospects of jaggery and Khandsari industry in India, Lukhnow, 60-61.

6. Nevkar, G.S, Patil, D.S. and Nale, V.N. (2011). Studies on standardization of jaggery powder production process. J. Agric. Res. Technol, 36(3), 490-492.

7. Rao, P.V.K, Das, M. and Das, S.K. (2007). Jaggery- A traditional Indian sweetener. Indian Journal of Traditional Knowledge, 6(1), 95-102.

8. Said, P.P. and Pradhan R.C. (2013). Preservation and value addition of jaggery, IJAE, 6(2), 569-574.

9. Singh, J, Singh, R.D, Anwar, S.I. and Solomon, S. (2011). Alternative sweeteners production from sugarcane in India: Lump sugar (Jaggery). Sugar Technol, 13(4), 366-371.

10. Sridevi, P. (2008). Development of process for manufacturing of granular jaggery. In: Processing, handling and storage of sugarcane jaggery, ed. Jaswant Singh, and R. D. Singh. Indian Institute of Sugarcane Research, Lucknow, 90.

11. Suwansri, S, Ratanatriwong, P. and Thanasukarn, P. (2009). Development of crystallized palm-syrup sugar as a natural sweetener. Asian journal of food and Agro-industry, 130-136.

12. Thakur, A.K. (1999). Potential of jaggery (Gur) manufacturing in Punjab state. Proceedings of the National Seminar on Status, Problems and Prospects of Jaggery and Khandsari Industry in India. Indian Institute of Sugarcane Research. Lucknow, India.

13. Unde, P.A, Adagale, P.V, Hashmi, S.I. and Raheem, A. (2011). Effect of different particle sizes of jaggery powder on storability. World Journal of Agricultural Sciences, 7(2), 157-160. 